\title{
Artigo
}

\section{As operações de paz da ONU como um mecanismo de neoliberalismo disciplinar: O caso de Angola (1988-2002)}

United Nations Peacekeeping as a mechanism of disciplinary neoliberalism:

The case of Angola (1988-2002)

Ana Rachel Simões Fortes ${ }^{1}$

DOI: 10.5752/P.1809-6182.2018v15.n3.p28

Recebido em: 04 de novembro de 2018 Aprovado em: 11 de maio de 2019

\begin{abstract}
Resumo
Este trabalho tem como propósito analisar as Operaçôes de Paz das Organizaçôes das Naçóes Unidas como um mecanismo de "neoliberalismo disciplinar", categoria cunhada pela Teoria Crítica das Relaçôes Internacionais. Sustenta-se que as operaçōes de paz foram responsáveis por introduzir ideias e práticas neoliberais de caráter tanto econômico quanto político em países debilitados pela guerra civil. Para tal pesquisa, o caso analisado trata das operaçôes de paz em Angola (1988-2002), prolongada em aproximadamente treze anos, e que foram determinantes no processo de reestruturação do Estado angolano.
\end{abstract}

Palavras-chave: Angola. Neoliberalismo Disciplinar. Organizaçôes das Naçôes Unidas. Operaçóes de Paz.

\begin{abstract}
The purpose of this paper is to analyze the United Nations Peacekeeping as a mechanism of "disciplinary neoliberalism", a category coined by the Critical Theory of International Relations. It is argued that peace operations were responsible for introducing neoliberal ideas and practices of both economic and political character in countries weakened by civil war. For this research, the case analyzed deals with peace operations in Angola (1988-2002), prolonged in approximately thirteen years, and which were decisive in the process of restructuring the Angolan State.
\end{abstract}

Keywords: Angola. Disciplinary Neoliberalism. United Nations. Peacekeeping.

1. Bacharela em Relaçóes Internacionais pela Universidade Federal Rural do Rio de Janeiro, mestranda em Relaçóes Internacionais pela Pontifícia Universidade Católica de Minas Gerais e membro do grupo de pesquisa sobre Potências Médias (GPPM- PUC Minas) Belo Horizonte/Brasil. ORCID 0000-0003-0159-793X 


\section{Introdução}

$\mathrm{O}$ processo de colonização portuguesa em Angola delimitou os primeiros traços de fronteira do país. Essa configuração se tornou um espaço de conflitos não só entre povos de diferentes culturas, mas também entre europeus que visavam a exploração de riquezas e domínio da regiáo. Em 1975, o país oficialmente se tornava independente, contudo, os problemas de caráter social, político e econômico estavam longe de ter fim. A Frente Nacional de Libertação de Angola (FNLA) ${ }^{2}$, o Movimento Popular de Libertação de Angola (MPLA), e, mais tarde, a União Nacional para a Independência Total de Angola (UNITA), principais responsáveis pela luta contra o colonialismo, disputavam entre si o controle do país. Esse cenário reflete uma Angola que até 2002 foi marcada por uma extensa guerra civil.

A década de 1990 foi, decerto, um dos períodos cruciais da história político-econômica angolana. O país passou de uma estrutura econômica socialista para uma economia de livre mercado. Além disso, pela primeira vez foram organizadas eleiçóes multipartidárias com o auxílio das Operações de Paz (OPs), elegendo o presidente José Eduardo dos Santos, consolidando-o no poder, haja vista que este já era presidente desde 1979. A marca desse período foi a intensificação do conflito entre o MPLA e a UNITA que buscavam incessantemente o domínio de todo o Estado.

Majoritariamente na África, onde os países passavam por conflitos civis neste período, como foi o caso de Angola, as OPs ficaram incumbidas de pacificar e reestruturar esses países debilitados pela guerra. Esses conflitos que assolaram a periferia foram considerados uma das maiores ameaças á segurança internacional do pós- Guerra Fria, desafiando a comunidade internacional em geral, e a

2. O FNLA, devido a problemas internos, acabou se diluindo na década de 80 , desse modo o conflito passou a ser travado entre a UNITA e o MPLA.
Organização das Nações Unidas (ONU) em particular, a responder às crises securitárias e humanitárias por eles geradas. Dessa maneira, uma nova era de ativismo impulsionou uma agenda para a paz, que se traduziu na emergência de um modelo de pacificação de natureza multidimensional, ou seja, de projetos baseado em preceitos neoliberais para além do comprometimento com a segurança.

Apoiadas neste cenário que as Operaçōes de Paz adquiriu funções pautadas também no auxílio de reconstrução desses Estados fragilizados. Sendo assim, o principal objetivo das OPs não ficou restrito a esfera da resolução de conflitos, mas contribuiu ativamente para a construção de políticas, economias e sociedades liberais, através de eleições multipartidárias, abertura econômica, apoio na criação de instituiçôes democráticas e propagação dos Direitos $\mathrm{Hu}$ manos. Nesta contexto,"os objetivos humanitários ganharam proeminência a partir da década de 1990, juntamente com o objetivo de promover soberania estatal a partir da dinâmica neoliberal”. (AKSU, 2003, apud SILVA, 2012, p.44).

Tendo como base esses elementos, buscou-se desenvolver uma pesquisa que ajude a compreender o papel das operaçóes de paz da ONU, analisando o caso de Angola (1988-2002), como responsável pela propagação de práticas neoliberais, por meio do auxílio no processo de reconstruçáo estatal. Para tanto, a partir da contribuição conjunta de pesquisadores da teoria crítica das Relaçôes Internacionais será possível apontar as contradições da imposição dessas diretrizes (provenientes do receituário liberal) em Angola.

$\mathrm{O}$ artigo encontra-se dividido em duas seçôes. Primeiro, será explorado o papel das operaçóes de paz em Angola, particularmente como esta foi responsável pelo processo de mudança estrutural do estado angolano, cujo objetivo principal foi colaborar por meio do discurso de segurança e paz, disseminar ideias e práticas neoliberais. E por fim, bus- 
car-se-á apresentar as contradiçóes desse processo de reconstrução estatal, que em termos de eficácia, possuem inúmeras críticas e limitaçóes.

\section{O papel das Operações de Paz na reconstrução político- econômica em Angola (1988- 2002): o disciplinamento neoliberal}

Apesar de ter seu início na década de 1950, as Operações de Paz foram se reformulando ao longo dos anos, ganhando um novo caráter especialmente nos anos 1990. Nesse período, houve um "casamento" entre as preocupaçóes com segurança e a implementação de mecanismos e instituições econômicas e políticas neoliberais. Essa lógica liberal era interpretada em torno de princípios, como a democratização e liberalização econômica. Ao longo da década de 90, houve um processo de institucionalização de princípios e procedimentos neoliberais oriundos do Consenso de Washington ${ }^{3}$ na constituição dessas operações, conduzindo os países periféricos debilitados pela guerra civil a adequar suas políticas como também economias ás iniciativas pautadas no receituário neoliberal.

Em vista disso, as OPs, propiciaram mais do que simplesmente a garantia da segurança; também possibilitaram mudanças estruturais internas em Estados que receberam os seus mandatos. De acordo com Bellamy (apud CHANDLER, 2013, p.1) o principal objetivo das operações de paz não ficou restrito à esfera da resoluçáo de conflitos entre Estados, mas contribuiu ativamente para a construção

\footnotetext{
3. Consenso de Washington é uma conjugação de medidas formuladas em novembro de 1989 por economistas de instituiçôes financeiras situadas em Washington D.C, como o FMI e Banco Mundial. Em 1990, essas medidas passaram a ser "receitadas" para promover o "ajustamento macroeconômico" dos países em desenvolvimento que passavam por dificuldades. Dentre as medidas, estão a disciplina fiscal, reduçáo de gastos públicos, privatização e desregulamentação de leis trabalhistas e econômicas.
}

de políticas, economias e sociedades liberais, através de eleiçôes multipartidárias, abertura econômica, apoio na criação de instituições democráticas e propagação dos Direitos Humanos.

No que se refere ao caso angolano, o envolvimento político das Naçôes Unidas em Angola iniciou-se no final dos anos 80. Em 1988 foi enviada a primeira missão de paz da ONU para Angola: a UNAVEM I (Missão de Verificação das Naçôes Unidas em Angola), cujo objetivo era acompanhar a retirada das forças armadas cubanas do território angolano, mas sem nenhum projeto imediato de implementação da paz. A UNAVEM I iniciou suas atividades em 3 de janeiro de 1989, contando com peacekeepers do Brasil, Argélia, Congo, Argentina e Índia. A missão passou por momentos difíceis, a retirada das tropas de Cuba chegou a ser suspensa, quando a UNITA atacou as forças daquele país, o que fez Fidel Castro anunciar a suspensão temporária da retirada de seu exército. "Após um mês de retaliação, Cuba iniciou novamente a retirada de seus militares e, em 6 de junho de 1991, a UNAVEM I completava seu mandato, com a saída completa dos soldados cubanos do território angolano". (PERCISI, 2015, p.65).

Por meio da Resolução $696^{4}$ do Conselho de Segurança em 30 de maio de 1991, foi instaurada a UNAVEM II, suas atividades consistiam também na fiscalização do cessar-fogo, interposição física e simbólica, monitoramento de fronteiras e apoio nas primeiras eleiçôes em Angola. Durante a UNAVEM II, foi estabelecido o acordo de Bicesse', assinado entre as partes conflitantes, mediado por Portugal e tendo a antiga União Soviética e os Esta-

4. Disponível em: < http://bdjur.almedina.net/item.php?field=item_id\&value=678934> Acesso em: 11 maio. 2017.

5. O acordo estipulou que seriam realizadas as primeiras eleições livres e democráticas em Angola, supervisionadas pelas Naçôes Unidas, assim como todas as forças beligerantes seriam integradas nas Forças Armadas Angolanas, cabendo ao Estado português, através das suas próprias forças armadas, ministrar a formação necessária. 
dos Unidos (EUA) como observadores. Este acordo é o primeiro sinal das OPs como um instrumento do Conselho de Segurança para apoiar na estabilização do Estado angolano a partir dos ideais de "paz liberal". Destarte, em $1992^{6}$, os angolanos foram pela primeira vez às urnas, organizadas pelos peacekeepers, para participar das eleiçóes presidenciais secretas e diretas.

Em 30 de setembro e 1 de outubro o Conselho Nacional Eleitoral (CNE), criado pela missão de paz das Naçóes Unidas, divulgou o resultado das eleiçóes, sendo José Eduardo dos Santos o representante eleito. A aparente paz se dissipou já que "o que estava previsto, porém, não aconteceu: logo após o resultado, a reação da UNITA tomou graves proporçóes e um retorno à guerra” (PERCISI, 2010, p 89). Além das eleiçôes, as reformas no campo econômico também foram realizadas. José Eduardo dos Santos do MPLA havia sido reconhecido pela comunidade internacional como presidente, anunciava, em 1992, mudanças na estrutura econômica. "Angola passou por uma transição, de uma economia centralizada, de caráter socialista, para uma economia de mercado, tendo como pano de fundo a relação com mercado petrolífero, principal produto de exportação e fonte de riqueza do país". (SOARES,2011 p.6).

O governo de José Eduardo dos Santos necessitava atrair investidores para o país, o que o levou, diante das pressóes, a se apoiar nas instituiçóes financeiras internacionais para tal objetivo. A busca pela organização política e econômica iniciava-se a partir da pacificação do território,

6. "Em 24 de junho de 1992, o Secretário-Geral das missóes de paz apresentou ao Conselho da ONU um novo relatório, em conformidade com a resolução 747 (1992), sobre as atividades da UNAVEM II e o processo eleitoral em Angola. Ele observou que os angolanos fizeram grandes progressos no processo de paz e que estavam recebendo assistência ativa dos três observadores - os Estados Unidos, a URSS e Portugal”. (ONU, 1992, p.194, tradução nossa). em que as OPs foram incumbidas de encontrar estratégias para minar o conflito e unificar Angola e assim torná-la o campo atrativo para a entrada de capital. Nesse sentido, podemos considerar que Angola passou precisamente pelo processo que Gill (2002) chamou de "neoliberalismo disciplinar”. Na concepção de Gill (2002), com a atual dinâmica financeira internacional, os governos precisam provar a sua credibilidade e a consistência das suas políticas para atrair a confiança dos investidores. Desse modo, era imprescindível as formulaçóes do Estado baseadas em reformas fiscais e estabilização política. Esse disciplinamento ocorre pelo fato que o crescimento econômico depende da necessidade de manter a confiança dos investidores, logo, os governos são levados a sustentar políticas que propiciem um "clima" favorável para o mercado financeiro.

Cada vez mais as OPs estavam inseridas e agindo nas questóes internas de Angola. Embora sua principal função fosse a garantia da segurança nacional do país, o que se viu foi o estabelecimento de embargos econômicos à UNITA, bloqueando seus acordos comerciais com os países vizinhos da África como a República Democrática do Congo, como forma de enfraquecer o grupo e disciplinar as relações comerciais do estado Angolano em âmbito externo. Este apoio do governo angolano aos princípios democráticos de mercado refletiu as muitas pressóes que enfrentou no início dos anos 90. A única perspectiva do MPLA de obter investimento externo e ajuda financeira para Angola foi negociar uma aproximaçấo com os Estados Unidos e as instituiçôes financeiras internacionais, que, por sua vez, exigiram a resoluçáo do conflito com a UNITA e o implemento de reformas democráticas e orientadas para o mercado.

A liberalização econômica e a implementação das eleiçôes multipartidárias não foram suficientes para conter a guerra civil que, a partir de 1994, to- 
mou grandes proporçóes. Nesse contexto, a ONU decidiu prolongar o mandato para a UNAVEM III por meio da assinatura do protocolo de Lusaka, dando assim mais um passo na tentativa de conter o conflito e reestruturar o Estado angolano.

Nota-se que com esse novo protocolo, as OPs passam a ter um caráter mais complexo, o que, segundo Maia (2006), reflete-se em um papel mais ativo na política angolana. Sua principal intenção, além do cessar fogo, era organizar um parlamento em Angola que pudesse garantir acentos a ambos os partidos rivais, com membros tanto do MPLA quanto da UNITA, assim como representantes do povo, viabilizando um cenário mais democrático e unificado no país, similares aos arquétipos dos países ocidentais centrais. Após muitos debates, desde a criação do protocolo de Lusaka, em 11 de abril de 1997, foi fundado o Governo de Conciliação Nacional (GURN), cuja função perpassa a busca por um entendimento interno - com a ocupação de postos no governo pela UNITA- com cargos de ministros, vice-ministros, embaixadores, governadores e vice-governadores das províncias.

A partir de maio de 1997, o Departamento de Operaçóes de Paz da ONU (DPKO), iniciou o apoio a expansão administrativa do governo de Angola, nas regiōes de Vila Nova, à leste, nas proximidades de Huambo, no distrito de Quibala, em Cuanza Sul e entre outros locais que estavam sob domínio da UNITA. Observa-se aqui que essas obrigações políticas, apoiadas pelas Nações Unidas, se aproxima do que Gill (2002) chama de novo constitucionalismo, uma vez que estâo associadas a direitos políticos, obrigações e procedimentos que dáo forma institucional ao Estado, definindo e delineando os direitos e obrigaçóes dos cidadãos a partir dos regimentos neoliberais.

Ademais, no mesmo ano foi instituído um "Plano Integrado para Direitos Humanos". Uma das prioridades do plano integrado era a realizaçáo de seminários de formação sobre a monitorização dos direitos humanos, os quais seriam oferecidos às forças e oficiais do governo do MPLA, mas também da UNITA. "Liberdade de expressão, acesso à educação, à saúde, à cultura foram discursos propagados durante o conflito, tendo como pano de fundo as OPs como as responsáveis por garanti-los a população angolana e, mais que isso, preparar o próprio governo para esse fim”. (PERCISI, 2015, p.95)

No relatório escrito em janeiro de 1998, o ex secretário-geral da ONU, Kofi Annan proferiu sobre o trabalho de monitorizaçáo dos direitos humanos, afirmando:

Com o resultado do prolongamento do conflito, Angola precisa de assistência internacional para desenvolver uma cultura voltada para o respeito pelos direitos humanos e liberdades individuais... Estamos adotando medidas no sentido de fortalecer a Divisão de Direitos Humanos, para continuar promovendo a conscientização e a investigação de denúncias de violação dos Direitos Humanos (HUMAN RIGHTS WATCH, 1999, p.29).

Podemos aqui traçar uma relação com a discussão sobre direitos humanos e neoliberalismo, tal como colocada por Harvey (2008). Segundo esse autor, a busca por legitimaçáo da paz gira em torno de um conjunto coerente de valores morais dos países centrais. Esse sistema liberal de direitos humanos tem por objetivo "não apenas a intervenção para proteger direitos humanos, mas também a criação de uma comunidade moral disciplinada" (HARVEY, 2008 p. 96). Sendo assim, se justifica o humanismo militar "em nome da proteção da liberdade, dos direitos humanos e da democracia”, todavia as raízes do atual humanitarismo baseado nos direitos humanos residem no crescente consenso de apoio ao envolvimento ocidental nos assuntos internos do mundo em 
desenvolvimento, com intuito de beneficiar a entrada do capital.

As permanentes violaçóes do cessar-fogo pelas duas partes levaram a Organizaçáo a alterar o caráter da missão. A Resolução 1118 do CSNU, de 30 de junho de $1997^{7}$, decidiu estabelecer uma nova missão de paz, a MONUA (Missão de Observação das Naçôes Unidas em Angola), cuja finalidade pressupunha mecanismos para reconciliação entre os dois partidos rivais. Contudo, cada vez mais o conflito se intensificava e a situação ficava mais complexa. Um fato marcante, que demonstra a fragilidade da posição da ONU naquele momento, foi o ataque da UNITA a dois avióes da organização, em dezembro de 1998, com a exigência de que os seus representantes se retirassem do país. (PERSICI, 2010)

Em fevereiro de 1999, o mandato da MONUA expirou e apenas ficou em funcionamento um escritório das Naçóes Unidas em Luanda (UNOA), tendo como principal função mediar as conversas e acordos entre as partes conflitantes. Segundo CES (2007), o trabalho da UNOA limitou-se às questóes humanitárias e ao reforço da capacidade institucional. Ainda, no mesmo ano, com as retiradas das tropas da ONU, as FAA- MPLA lançaram inúmeros ataques ao exército da UNITA, fazendo-as sair dos territórios ocupados. Desse modo, "o único meio para se alcançar a paz, na ótica do governo de José Eduardo dos Santos "era por meio da guerra" (PERCISI, 2010, p.91). Dessa maneira, o grupo rebelde começou a perder o acesso das principais áreas da exploração de diamantes e de sua riqueza acumulada durante anos, houve uma diminuição de grande parte do seu financiamento, o que acabou por acarretar em sua falência.

7. UN, Archives and Records Managent Section- 1997 Disponível em: <https://archives.un.org/sites/archives.un.org/ files/files/Finding\%20Aids/2015_Finding_Aids/AG-027.pdf>Acesso em: 20 set. 2017
O fim do conflito angolano somente ocorreu em abril de 2002, após a morte do líder da UNITA, Jonas Savimbi e do reconhecimento da vitória militar do MPLA. Por meio da assinatura do Memorando de Luena ${ }^{8}$ este acordo de paz levou à Resoluçáo 1433 do Conselho de Segurança de Agosto de 2002, responsável pelo estabelecimento da Missão das Naçôes Unidas em Angola (UNMA) com a atribuição de apenas fornecer 30 observadores militares para monitorar as áreas de aquartelamento e a incorporação de soldados da UNITA a FAA.

Este processo de conciliação nacional procurou compilar ambos os partidos rivais que detém maior poder no país, tanto no que se refere a capacidade econômica quanto política. Todavia, tudo isso ocorreu sem uma participação ativa da população que estava altamente vulnerável com a guerra civil. Era claro que "o projeto de conciliaçáo nacional tinha como principais atores e interesses das elites locais e internacionais, intermediadas diretamente pela ONU, que buscava alternativas para o alcance da paz, ao prescrever uma série de direitos e obrigaçóes a toda nação angolana" (SOARES, 2011, p. 7).

Em suma, observa-se que, em Angola, a proposta da garantia da paz tomou um formato para além dessa temática, envolvendo questóes de liberalização econômica e eleições multipartidárias. Por conseguinte, na leitura de Paris (2004, p.65), "as Operações de Paz não foram apenas um exercício de gestão do conflito, mas parte de um esforço internacional mais amplo para transformar Angola, de um Estado de partido único em guerra, para uma pacífica e próspera democracia de mercado".

8. United States of Peace, Angola peacebuilding. 2000. Disponível em: < http://www.usip.org/sites/default/files/file/ resources/collections/peace_agreements/angola.pdf $>$. Acesso em: 20 set. 2017. 


\section{As contradições desse processo de reconstrução estatal e do estabelecimento da paz}

As operaçóes de paz em Angola, em termos de eficácia, possuem inúmeras falhas e críticas devido às suas limitações em planejar uma estratégia coerente de combate ao conflito. Maia (2006, p.198), ressalta que a ONU procurou implementar um amplo projeto de regulação em Angola, sendo o objetivo primordial a normalizaçáo deste país. Todavia, com a pacificação e a reunificação do território e da população de Angola, o que os observadores de todo o processo assistiram, com o passar dos anos, foi justamente o oposto, ou seja, o aprofundamento e a expansão do conflito civil, acompanhado por uma das maiores tragédias humanitárias da contemporaneidade.

$\mathrm{O}$ insucesso dos projetos de acordos de paz para Angola possui múltiplos fatores, tanto relacionados a interesses internacionais quanto razóes internas, que incitaram o recrudescimento da guerra civil angolana. A postura da ONU foi passível de questionamento durante todo o empreendimento para a pacificaçáo no local, na efetividade de suas medidas, como também sobre os seus reais interesses. O fato é que durante quase todos os mandatos (UNAVEM II, UNAVEM III, MONUA), nem as intimações, nem as sanções emitidas pelo conselho de segurança contra a UNITA surtiram efeito consistente. "A UNITA não apenas agiu com descaso com relação a tais condições, como cumpriu muito ligeiramente as sanções, burlando -as assim que possível” (MAIA, 2006, p.199).

A UNAVEM I foi concluída com êxito em 1991. Entretanto, foi a partir da UNAVEM II que as OPs se tornaram mais complexas, uma vez que suas atividades ultrapassaram o viés militar. Conforme já exposto, a implementação das eleiçôes multipartidárias resultou em substancial acentuação do conflito, já que a UNITA se negou a aceitar. Além disso, "os interesses das grandes potências, mais especificamente os EUA, influenciaram implicitamente no decorrer da guerra civil" (MAIA, 2006, p.200).

À posteriori, a situaçáo acabou por se agravar e as expectativas de reconciliação nacional e de pacificação ficaram cada vez mais difíceis. Diante desse fato, o que deve ser levado em consideração é que, apesar do reconhecimento do governo do MPLA pela comunidade internacional, havia inúmeras incertezas sobre os desdobramentos dessas disputas, de modo que a ONU foi acusada de ser omissa em relação a restrição das atividades de Jonas Savimbi.

O mesmo pode ser notado a partir da formulação da UNAVEM III, sendo que a UNITA continuava a rejeitar o acordo de paz e, cada vez mais, ameaçava a situação angolana. Embora tenha havido ampla mobilização de monitoramento das OPs nesta terceira missão, não conseguiram desmembrar o exército da UNITA, nem o desarmar suas tropas. Tal qual as missóes anteriores, a ONU não reagiu de forma firme em relação ao movimento rebelde e foi flexível e indulgente com o grupo em algumas circunstâncias. Além disso, "a troca do representante geral da ONU na missão fez com que a estratégia para a consolidação da paz modificasse, o que gerou ainda mais instabilidade e desordem em todo o processo" (TIBURCIO, 2009, p.60).

Tiburcio (2009) constata que as sucessivas debilidades dos protocolos, acordos e sanções reforça a premissa de que a chave para a viabilidade do processo de paz não se encontrava apenas na recusa de Savimbi em ter um compromisso inequívoco com a paz, mas sim no reconhecimento de que sua opção pela guerra era plausível devido à existência de atores, recursos e espaços interessados na continuaçáo da mesma, já que a UNITA recebeu muitos investimentos. 
De acordo com Soares (2011, p.306), "as missões de paz compartilham uma série de pressupostos de paz liberal que colocam a democracia e o mercado livre na vanguarda dos esforços de reconstruir o Estado debilitado". Seu objetivo não é a restauração do status quo, mas a construção de uma sociedade e política sobre linhas liberais. Para Soares, Angola é um exemplo de um processo substancialmente de reconstrução iliberal, onde as elites locais e internacionais definem o tipo de sociedade pós-guerra que eles querem construir.

Cox (2007, p. 117) similarmente argumenta sobre a ambiguidade da implementaçáo de uma ideologia dominante nos países periféricos. Ao se referir à hegemonia ${ }^{9}$ como estrutura política e econômica dominante, o autor explica que ela é fundada por Estados poderosos que, para introduzi-la passaram por uma revoluçáo social e econômica completa durante a implementação desse bloco hegemônico, em toda esfera da sociedade civil/política. Essa revolução não só modifica as estruturas econômicas e políticas internas do Estado em questão, mas também se expande para além das fronteiras do Estado. No caso dos países periféricos ela se da por meio da revolução passiva.

As instituições econômicas e sociais, a cultura e a tecnologia associadas a essa hegemonia nacional tornam-se modelos a serem imitados no exterior. Essa hegemonia expansiva é imposta aos países mais periféricos como uma revolução passiva. Esses países não passaram pela mesma revolução social completa, nem têm suas economias desenvolvidas da mesma forma, mas procuram incorporar elementos do modelo hegemônico sem que as antigas estruturas de poder sejam afetadas. "Embora os países periféricos possam adotar alguns aspectos econômi-

9. O conceito de hegemonia na ordem mundial não se baseia apenas na regulação do conflito interestados, mas também numa sociedade civil concebida globalmente, isto é, num modo de produção de extensão global que gera vínculos entre as classes sociais dos países nela incluídos. (COX, 2007, p.113) cos e culturais do núcleo hegemônico, têm menos condiçôes de adotar seus modelos políticos" (COX, 2007, p.118).

Em outras palavras, as premissas neoliberais são mais intensas e coerentes nos países centrais e contraditórias na periferia. Isso decorre do fato de que as estruturas políticas, econômicas e culturais não são desenvolvidas conforme no centro, e mesmo incorporando (ou sendo imposto) elementos neoliberais, suas antigas estruturas de poder não são substituídas por completo. Angola, de certo modo, adotou algumas orientaçóes neoliberais estipuladas pela ONU, como a liberalização econômica, no entanto em relação a adoção ao modelo político não foi da mesma forma. Todo esse processo de democratização e reconciliação nacional foi adquirido de maneira falha e passível de questionamentos, de modo que os preceitos de paz liberal, liberdades civis, estado de direito e redução da desigualdade, não são exercidos de forma coerente como é proposto e desempenhados nos países centrais.

Com efeito, apesar de ter alcançado a estabilidade política, com assinatura do Acordo de Paz em 2002. Ainda hoje, Angola sofre com as consequências da guerra civil, mesmo apontando nos últimos anos altas taxas de crescimento econômico, a desigualdade social e a dependência de capital externo são os maiores entraves e desafios que o país enfrenta. Nas palavras de Soares (2011) este processo de reconstrução foi gerido, na verdade, pelas elites locais e por interesses externos, baseado nos preceitos liberais, mas que de fato não foram executados com tal característica como nos países de onde estes preceitos foram criados.

\section{Considerações Finais}

Conforme apontado durante o artigo, a partir da década de 90, com a nova dinamização do sistema internacional e principalmente do mercado financei- 
ro, Angola necessitava atrair investimentos. Isso conduziu o país a colocar-se na órbita das instituições internacionais, levando a uma reestruturação da sua economia e das suas instituiçóes governamentais. Esse período foi marcado por profundas mudanças na estrutura estatal angolana, com novas diretrizes no que se refere a política e a economia, estabelecidas com a implementação do multipartidarismo, seguida, em termos econômicos, da passagem de uma economia centralizada, conduzida pelo partido MPLA de caráter socialista, para uma economia de mercado.

Nesse cenário, constantemente as operaçôes de paz atuaram nas questóes internas de Angola. Embora sua principal função fosse a garantia da segurança nacional do país, o que se viu foram as missóes de paz como mentora da primeira eleição multipartidária no país e do estabelecimento de embargos econômicos a UNITA, como forma de enfraquecer o grupo e disciplinar as relaçóes comerciais do estado em âmbito externo. Ademais, elas foram responsáveis pela criação do Governo de Conciliação Nacional (GURN), cuja função era a busca por um entendimento interno, como também implementaram a Unidade dos Direitos Humanos.

A ONU procurou implementar um amplo projeto de regulaçáo em Angola, sendo o objetivo primordial, a normalizaçáo deste país. Contudo, o que os observadores de todo o processo assistiram, foi justamente o oposto, ou seja, o aprofundamento e a expansão do conflito civil. Nota-se a partir desta investigação que as operações de paz contribuíram ativamente para a construção de políticas, economias e sociedades liberais, através de eleiçóes multipartidárias, abertura econômica, apoio na criação de instituições democráticas, propagação dos Direitos Humanos, entre outros. Essas missóes foram justificadas em prol da proteção da liberdade e da paz, todavia esse humanitarismo na verdade está enraizado no crescente envolvimento ocidental (das grandes potências) nos assuntos internos dos países em desenvolvimento.
Cabe salientar também que mesmo com a estabilização política a partir de 2002, os desafios do país ainda são de grande proporção. Observa-se, por exemplo, que o índice de desenvolvimento humano do país que é um dos piores do mundo. Os maiores gastos públicos continuam sendo destinados para área da defesa, mesmo com o fim da guerra civil, tornando Angola o país que mais investe em militarização na África Subsaariana. Outro aspecto importante a ser pensado é o fato do Estado angolano, desde a independência, ser governado apenas por um partido, o MPLA ${ }^{10}$, tendo José Eduardo dos Santos conduzido o país por 38 anos, o que indica os traços de uma estrutura estatal oligárquica do país. Mesmo alcançando a estabilidade política, os problemas de caráter social enraizados na sociedade ainda não foram superados. Sendo assim, pode-se concluir que este processo de reconstrução foi gerido na verdade por interesses externos, baseado em disciplinas neoliberais, mas que de fato são passíveis de controvérsia.

\section{Referências}

BIGATÃO, Juliana de Paula. Do fracasso à reforma das operaçóes de paz das Naçóes Unidas(2000-2010). Tese de doutorado em Relaçóes Internacionais UNESPIUNICAMP। PUC-SP: São Paulo, 2015.

CAVALCANTE, Fernando. Os reflexos da paz liberal na abordagem das Naçôes Unidas à consolidação da paz na Guiné-Bissau. Revista Crítica de Ciencias Sociais, Coimbra Vol.102 pp.21-42.2013

CHANDLER, David. The Uncritical Critique of 'Liberal Peace. Review of International Studies, v. 36, 2010, p.137-155. COX, Robert. Gramsci, hegemonia e relaçóes internacionais: um ensaio sobre método. In: GILL, S. Gramsci: materialismo histórico e relaçôes internacionais. Rio de Janeiro: Editora UFRJ, 2007, p. 101-124.

GAMA, Carlos Frederico. Após a guerra, estabilidade? Mudanças nas operaçóes de paz da ONU (1992-2000). Paco editorial, 2016.

GILL, Stephen. Power and Resistence in the New World Order. New York, Palgrave Macmillan. 2002, 2008.

10. Cabe salientar que o atual presidente de Angola, José Lourenço, também é do partido MPLA. 
GILL, Stephen. The constitution of global capitalism. Los Angeles, The International Studies Association Annual Convention, 2000.

HARVEY, David. O Neoliberalismo: História e Implicaçóes. São Paulo, Ediçóes Loyola, 2008.

HUMAN RIGHTS WATCH. Angola Explicada. https:// www.hrw.org/legacy/portuguese/reports/angopor/entirebook-12.htm. Último acesso em: 29 out.2017.

MAIA, Tatiana A intervençáo das Organizaçóes das Naçóes Unidas em Angola (1988-1999). Dissertação (Mestrado) Universidade Federal do Rio Grande do Sul. Mestrado em Relaçôes Internacionais- Instituto de Filosofia e Ciências Humanas. Porto Alegre: 2006.

ORGANIZAÇÓES DAS NAÇÓES UNIDAS. Examen de cuestiones relacionadas con la responsabilidad del Consejo de Seguridad de mantener la paz y la seguridad internacionales. http://www.un.org/es/sc/repertoire/89_92/89-92_08. pdf. Último acesso em: 29 out.2017.

ORGANIZAÇÓES DAS NAÇÓES UNIDAS .Peacebulding Comission. http://www.un.org/en/peacebuilding/. Último acesso em: 29 out. 2017.

ORGANIZAÇÓES DAS NAÇÓES UNIDAS.MONUA Angola. http://www.un.org/en/peacekeeping/missions/past/ monua/monua.htm. Último acesso em: 29 out.2017.

PARIS,Roland . At War's End Building Peace After Civil Conflict. Cambridge University, 2004.

PERSICI, Rosana Sarmento. Guerra e paz em Angola: um estudo sobre o papel da ONU e das grandes potências. Dissertação (Mestrado) - Pontifícia Universidade Católica de Minas Gerais. Programa de Pós-Graduação em Relações Internacionais. Belo Horizonte, 2010.

SILVA, Francine Rossone. A paz liberal nas operaçóes de peacebuilding: o "local” e os limites da crítica. Dissertação (mestrado) - Pontifícia Universidade Católica do Rio de Janeiro, Instituto de Relações Internacionais, 2012.

SOARES, Ricardo. Iliberal Peacebulding in Angola. J. of Modern African Studies, v.49, n.2, 2011, p. 287-314.

SOARES, Ricardo. África desde o fim da Guerra Fria. Relaçóes Internacionais, 2009, p.99-116.

SOUZA,Adriano; SILVA, Denio; DILLMAN Mariana; GUEDES Mauro; LEITE Sheila Guerra civil e o desenvolvimento econômico em Angola. Revista de Economia, Anápolis, v.7, n.2, 2011, p. 1-21.

TIBURCIO, James. Paz e Guerra em Angola: Um estudo exploratório. Dissertação (Mestrado) Universidade de Brasília. Programa de Pós-Graduação em Relaçôes Internacionais. Brasília, 2009.

VISENTINI, Paulo Fagundes. A África na política internacional: o sistema interafricano e sua inserçáo mundial- Coleção Relaçôes Internacionais: África. Curitiba: Juruá, 2010. 